Published in Railean, E. A. (ed.) Assessment, Testing, and Measurement Strategies in Global Higher Education. Advances in higher education and professional development. Hershey, Pennsylvania, USA: IGI Global. ISBN: 978-1-7998-2314-8.

\title{
Chapter 3 \\ Flipped Learning With Peer Reviews in the Introductory CS Course
}

\author{
Pia Niemelä \\ iD https://orcid.org/0000-0002-8673-9089 \\ Tampere University, Finland \\ Aulikki Hyrskykari \\ Tampere University, Finland \\ Timo Poranen \\ Tampere University, Finland \\ Heikki Hyyrö \\ Tampere University, Finland \\ Juhani Linna \\ Tampere University, Finland
}

\begin{abstract}
Today, university pedagogues in Finland are keen on applying flipped learning techniques to improve education and learning outcomes. In accordance, assessment moves to a more formative and flipped direction as well. Flipped learning implies assessment to be continuous, yet controversially, resources in education are decreasing. The dilemma can be partly solved by increasing self-, peer-, and automatic assessment, and in addition, the exploitation of learning analytics. Tampere University has addressed these pedagogical demands and challenges in computer science courses by developing a learning management system called WETO. This supports flipped learning techniques in a resource-wise way by enhancing assessment with new peer-review options, self reflection, and negotiations. This chapter highlights the proven and functional practices of formative assessment based on an introductory computer science course supported by WETO. It discusses further development needs and opportunities of learning management systems from this viewpoint.
\end{abstract}

DOI: 10.4018/978-1-7998-2314-8.ch003

Copyright $\odot$ 2020, IGI Global. Copying or distributing in print or electronic forms without written permission of IGI Global is prohibited. 


\section{INTRODUCTION}

Generation $\mathrm{Z}$ will face a new flexible working life requiring so-called 21 st century skills. The skills comprise thinking, working, and living skills, and digital fluency and digital literacy as all-encompassing tools and enablers. Moravec (2013) itemizes thinking skills as creativity, innovativeness, co-operation, motivation, and quick combinations of new ideas; working skills as digital literacy, exploitation of free and open learning resources, horizontal knowledge networks, and socially constructed understanding; and living skills as continuous updates of one's knowledge, that is, lifelong learning, but, on the other hand, a relaxed attitude towards failures and resilience. As the requirements for future working skills change, education should adapt and ensure, that also digital-literacy skills of the generation $\mathrm{Z}$ are adequate.

Training students adequately for future working life necessitates also the evaluation and development of teaching methods. The methods should, for example, employ exercises that in addition to digital skills emphasize co-creation, collaboration, transparency, and sharing results. In consequence, new innovative digital pedagogy and learning management systems need to be developed.

Learning management systems (LMSs) have progressed from simple pdf document and course grade repositories into ones promoting social interactions and collaborative problem solving among participants. In addition to formal learning resources, students exploit extensively online materials such as videos, games, virtual worlds, and free online MOOCs, which further foster informal learning that blend with formal education (Gros and García-Peñalvo, 2016).

Flipped learning and assessment exemplify such methods that prepare students for the 21 st century, and for the requirements of a new flexible working life. Flipped learning (FL) and flipped classroom (FC) are trends with a promise of improved and intensified learning. This paper describes the steps towards flipped learning in one introductory computer science course arranged at Tampere University, and examines the assessment practices enabled by a self-developed LMS, WETO, in particular. The main questions we address in this paper are:

RQ1: What are the means to increase formative assessment in the introductory computer science course with plenty of exercises that are difficult to assess automatically?

RQ2: How are the teaching arrangements, and the applied self- and peer-review practice in particular, perceived among the course participants?

RQ3: What is the current level of support for self- and peer-reviews in the selected LMS?

The paper is organized as follows: Section 2 contains a review of current discourse about flipped learning, Section 3 describes the research context of this study, Section 4 introduces the results, and Section 5 discusses the results, validity considerations, and the future ideas to improve the approach.

\section{A PEDAGOGICAL RATIONALE FOR FLIPPED LEARNING}

Current society extends flexibility and increases uncertainty, which requires of young people self-regulation skills and identity work as specified by self-determination theory (SDT) (Ryan and Deci, 2000; Deci, 1971; Deci and Ryan, 2010). SDT consists of autonomy, relatedness, and felt competence that largely determine the self-confidence of a worker of the 21 st century. Supposedly, competence increases naturally by deepening substance knowledge. 
In accordance, tasks must be suitable for a learners' skill level: not too easy to prevent boredom, and not too difficult either to prevent frustration, quoting Bandura (2010): 'The most effective way of creating a strong sense of efficacy is through mastery experiences.' It is possible to differentiate students' learning with the help of learning analytics and other statistical means. In games, for example, the level of performance increases gradually, which maintains the interest of players. In engaging students, gamification and other challenge-based activities have proven to be effective thus an ideal LMS should borrow some practices from games. If motivating exercises are combined with a good and rewarding user experience by complying with the factors of SDT theory, autonomy, adequate amount of social interaction, and felt competence, it should result in a rewarding learning experience.

\subsection{Principles of Flipped Learning}

The principles of SDT theory are actualized in flipped learning. The flipped methodology attracts teachers seeking a more student-centered way of learning after the domination of traditional learning culture. First, in the model of flipped learning, students familiarize themselves with materials, such as text, videos and podcasts, and complete pre-tasks before arriving at a contact lesson or lecture. In contrast to the past, lectures are not merely based on teachers' monologues, but instead on collaborative tasks such as group work targeting information retrieval and deepening skills (Chen, Wang, Chen, et al., 2014). Problems encountered are solved together. In the end, a teacher dedicates special time for reflections and group evaluation referred to as primetime (Koskinen, Lämsä, Maunuksela, Hämäläinen, and Viiri, 2018).

In the literature, two overlapping terms are used: flipped learning and flipped classroom. Toivola and Silfverberg (2015) unveil the difference between flipped learning and flipped classroom to be separable in the continuum of teacher- to learner-centered didactic approaches, see Figure 1.

In the flipped classroom, a teacher still keeps control of deciding what will happen in the classroom, selects learning material, and sets a suitable time for learning. A flipping teacher dares to give up direct

Figure 1. The dimensional view of didactic approaches in the continuum from directed teaching towards learner-centered learning according to Toivola and Silfverberg (2015)

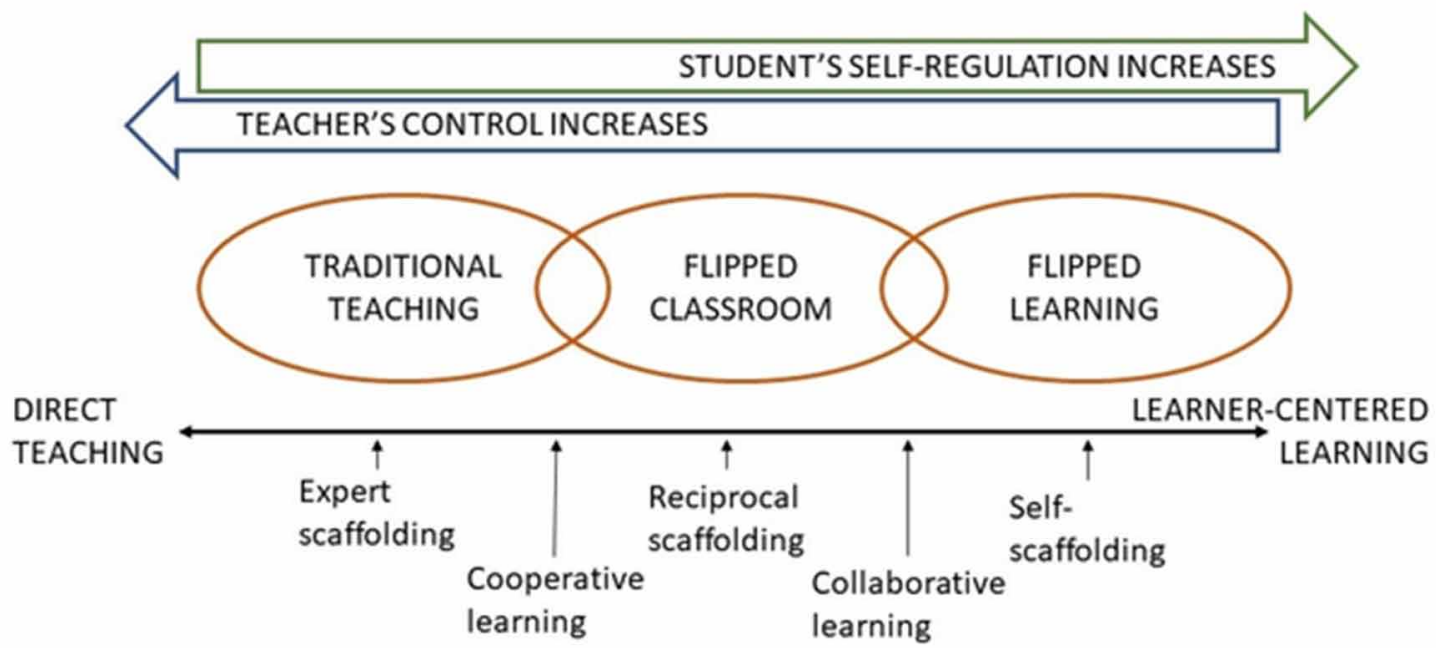


control and trusts students' ability and desire to learn, thus transferring more responsibility to their students. This changes the climate of learning. Now, students have an opportunity to solve problems independently without first asking a teacher or studying a textbook. Students can influence their own study speed and learning trajectory by concentrating on elements appropriate to their learning style and interests. This requires self-knowledge, autonomy, self-regulation skills, and motivation.

The strength of flipped learning, namely increased autonomy and responsibility may turn out to be the biggest problem for adopting the flipped learning approach. Online learning can also cause anxiety as it can be perceived as too open and unstructured. Instead of the anticipated empowerment, students may be left overwhelmed and clueless as how to proceed and study.

\subsection{Debate About Digitalization and Flipped Learning}

In her dissertation, Saarinen (2018) emphasizes that the current tendency of increased autonomy hits hardest such risk groups as poorly-schooled male students, and children of immigrant and low-income families, mainly because the support at home is low or non-existent. As a remedy, Saarinen recommends the presence of supportive and confidential relationships in constructing a more mature character, cooperativeness, and better self-regulation skills. She also points to a correlation between increased digital learning and deteriorating learning outcomes, see e.g. PISA-2015 (OECD, 2015), which has led to debate among Finnish educators.

Critics have pointed out the timing: based on the PISA-2015 results it is too early to claim that digitalization, and technology-enhanced, self-regulated learning towards the flipped direction are the root causes of declining results - the Finnish National Curriculum was taken into use only in 2016 (Järvilehto, 2018). However, the claimed error in timing of Saarinen's research is not that significant: the invasion of technology and the trend of more autonomous learners have been strengthening since the beginning of the new millennium and have only accelerated during the last years of 2010's.

Toivola (Toivola, 2018; Toivola and Silfverberg, 2015; Toivola, 2016; Toivola, Peura, and Humaloja, 2017), as the principal flipped learning advocate of Finland, criticizes this tone of debate. She pigeonholes it as the usual resistance of an old-school, teacher-centered establishment. Toivola's counter-argument is that the establishment in the domain of education has not challenged itself in the process of changing society - and its own practices. In explaining the failure in inaugurating the new means of learning and technology, Toivola points out the arrogance and pride of old-school establishment, disguising the fear of failing. Indeed, maybe Toivola should be listened to more carefully than far-from-praxis scholars, since she has also proven FL to work for her high-school students. Manifestly, she often labels her writings as 'the struggle against flat heading people during their school path' - flat heading meaning the act of making homogeneous and equalizing.

She does not see 'forced' equity as a core value anymore, but autonomy: 'Supporting students' autonomy is not an optional choice for teachers, but an obligation that is mandated by the 2016 HighSchool Curriculum'. However, poor students are not determined to fail: 'Self-regulation is not a skill that a person has or does not have, but a capability that can be developed continuously.' In her blog, Toivola quotes the research by Hattie (2008, 2012): as follows: 'the most important thing in learning is learning to learn and supporting self-regulation', and, 'pupils who are best able to assess their own skills in relation to the objective to be achieved learn best. The best learning outcomes are provided by a teacher who looks at learning through the pupil's eyes and helps students become their own teachers.' In supporting the process of learning to learn and self-regulation, a teacher is mandated to support 
adequately especially students with poor self-regulation, otherwise they will be lost in the abundance of opportunities.

Norrena (2016) describes the development of a self-regulated learner as a succession of phases of dependence on a teacher followed by the phases of interest and commitment, and finally, self-regulation, provided that the process is successful. In the beginning, teaching should begin as very structured with clear learning objectives in compliance with the theory of constructive alignment (Biggs, 1996). Only after students' interest has been captured, the supervision should alter to be more implied, towards motivation and encouragement for students to progress themselves independently. In the next step of commitment, learners desire more for a listener and a collaborator instead of a director. Ultimately, setting long-term goals begins to be within the limits of students' abilities in the final phase, when such meta-cognitive skills are in place that further development is more and more self-nourishing: students have reached the anticipated level of self-regulation.

Consequently, in the very beginning of the studies the amount of support should be at its greatest. For example, in the first computer science courses at university (CS1), the number of dropouts has been successfully decreased with well-designed scaffolds (Haatainen, Lakanen, Isomöttönen, and Lappalainen, 2013). The successful dropout interventions include innovative systems to predict dropout, early intervention and follow-up (Whitehill, Williams, Lopez, Coleman, and Reich, 2015), and beside decreasing the number of dropouts, learning analytics can be utilized to improve the quality of education and to enable students to review and evaluate their own progress (Sclater, Peasgood, and Mullan, 2016). The level of support should be chosen carefully, not to "spoon-feed" students, which has been shown to reduce the learning outcome (Vanderhyde, 2019). Skills supposed to be learned in the current course must not be assisted too much, whereas future learnable skills can be scaffolded. Thus, the amount of autonomy required of students should increase gradually, and be at its largest only at the end of their studies in preparation for a smooth transfer to the 21 st century working life.

\section{METHOD AND RESEARCH CONTEXT}

In the next chapter we will report where an introductory computer science course has succeeded and failed over the years when evolving towards flipped learning principles. However, in this chapter we will first describe the course from which the data for this study has been collected.

\subsection{Development of the CSO Course}

The course is called Tietotekniikkataidot (Computing Skills in English), and is referred to subsequently as CSO (Hyrskykari, Linna, Sand, et al., 2017; Hyrskykari, Linna, and Sand, 2019). We are studying its evolution between the years 2005-2019. Rapidly changing requirements have forced the course to evolve term-by-term.

In the domain of education, design-based research (DBR) is a methodology where a cyclic process is reflective, all stakeholders contribute to the result, and it is coupled with some background theory. Other terms for the method exist, such as learning design or design for learning (Laurillard, 2013; Beetham and Sharpe, 2013). DBR systematizes a course development in a cycle of design, development, enactment, and analysis (Wang and Hannafin, 2005; Anderson and Shattuck, 2012; Ørngreen, 2015). Here, the cycle represents a course term, which inserts new requirements into the redesign of the next course 
(The Design-Based Research Collective, 2003; Van den Akker, Gravemeijer, and McKenney, 2006; Collins, 1992). Moreover, the redesign includes 'reflective conversation with the situation' (Schön, 1992), whereby course staff observe the effects of new arrangements and refine them if necessary.

In the design phase, the learning objectives of the course are checked and harmonized with the content of other courses and the objectives of the curriculum. Development is mainly executed by the course personnel, but it is not immune to new trends in education. For example, the emphasis on flipped learning and formative assessment with peer-review rubrics may partly be traced back to contemporary influences of pedagogical discourse. Enactment includes reflections on the functionality of new changes by the lecturer and teaching assistants.

On completing the course, the students are asked to give feedback, which is used as the data for this study. The analysis of the course is based on both students' qualitative and quantitative feedback, and their learning outcomes, as well as the reflections of the course personnel. Student feedback has been collected since the academic year of 2005-2006, when WETO and peer-review practice were taken into use for the first time. Regular comprehensive feedback two or three times a year offers ideal circumstances to experiment with different design solutions. These solutions are designed and developed in a close collaboration between software developers, teachers, and teaching assistants guided by student feedback.

\subsection{CS0 Course Introduction}

Originally, the CS0 course functioned as a primer for students having computer science as their major. The course had less than a hundred students annually, and the implementations were traditional with theoretical lectures and regular, compulsory, weekly hands-on assignments. In the mid 2000's, the skills taught on the course became more applicable for all students and cohorts started to grow rapidly (Figure 2). This altered the course content towards more practical and generic topics, which consequently produced even more enrollments from other degree programs.

\section{Growth of the Course}

Still in 2004, compulsory hands-on assignment sessions were held in groups of twelve students and marked by a teacher in situ. With a growing number of enrollments, it became apparent that teaching had to be arranged in a different way, and the development of a new LMS, WETO (WEb Teaching Organizer), was launched. The design of the system started with especially a formative assessment in mind. This happened at the same time as LMS-supported online courses started to emerge around the world, and the emergence of massive open online courses, MOOCS, was just beginning (Baturay, 2015).

Currently, the course is now university-wide and mandatory for the first-year students in almost all degree programs. Thus, about 1400 students enroll in the course each year. Until the academic year 2017-2018, three implementations were run annually, with 200-600 students on each implementation. Due to a decrease in teaching resources, one implementation was removed, thus, in 2018-2019, the course was run only twice. About 1300 students registered for first period implementation in the autumn, and about 200 students, who missed or dropped out from the autumn implementation, took the course in the spring. 
Figure 2. Annual course sizes

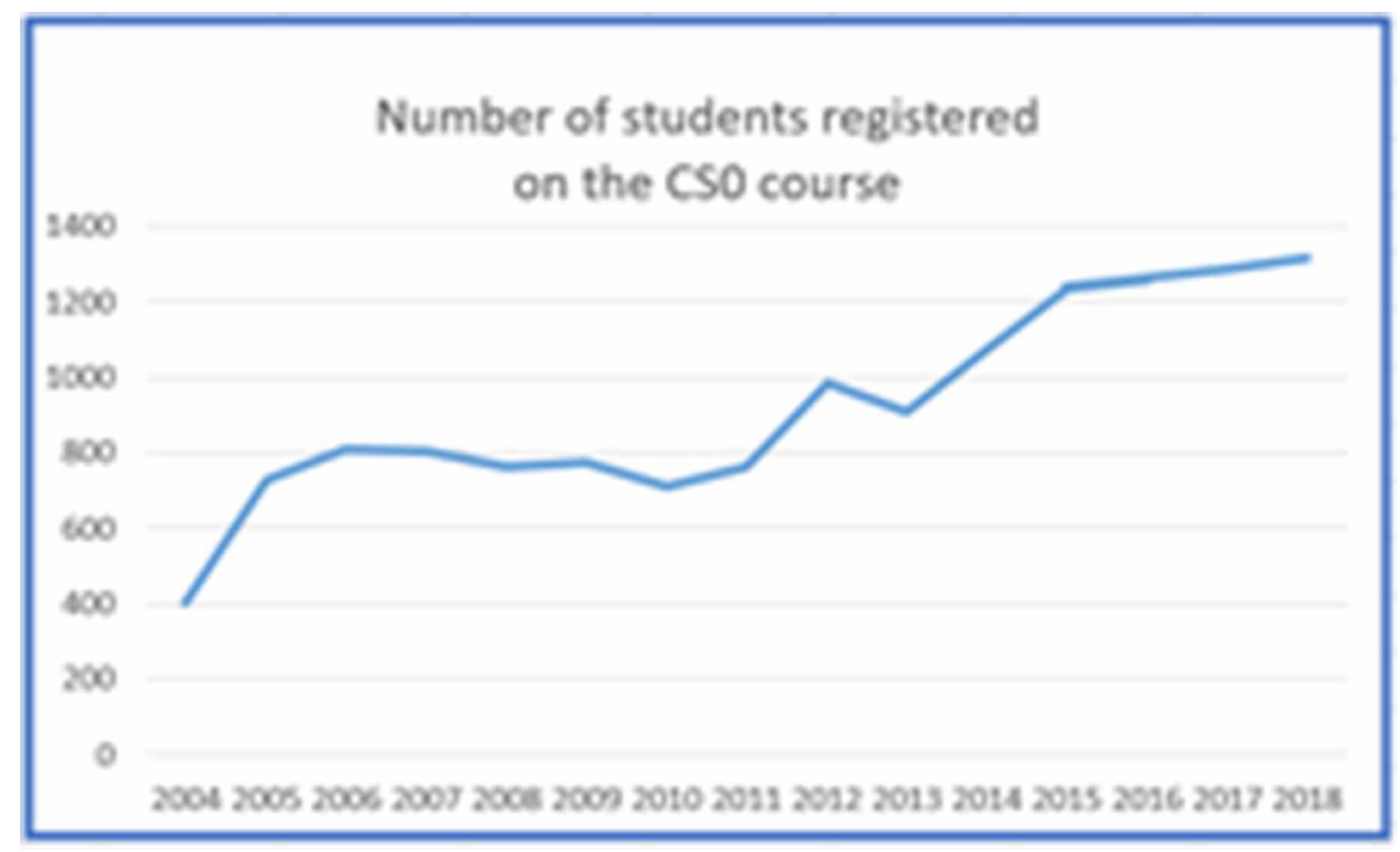

\section{Learning Objectives of the Course}

The objectives of the course are to introduce and to familiarize students with the university computing environment, to learn and practice with up-to-date general IT skills needed during studies and professional life later on, to build up the abilities to maintain and update study skills, and to encourage autonomous learning. Since the course aims to provide students not only with knowledge but with hands-on skills, the fundamental design principle of the CS0 course is learning by doing. Students have to rehearse their newly acquired skills with plenty of computer lab exercises. A three-hour kick-off lecture starts the sequence of ten weekly lectures.

The following course topics have been covered in most of the implementations, although the course syllabus requires constant updating, and changes are made every term:

1. Effective use of operating systems

2. Learning environments, email, collaboration and teamwork

3. Handling data in the web environment, managing bibliographic data and references (browsers, cloud services)

4. Word processing principles

5. More advanced tools of word processing

6. Spreadsheet principles

7. Using spreadsheet functions and visualizing data

8. Image processing 


\section{Publishing on web}

10. Presentation software

A few course implementations (2005-2007) familiarized students with academic writing tools such as referencing techniques and management. However, these were dropped since marking essays was too time-consuming, let alone writing reliable instructions for peer-reviewing essays. Additionally, the teachers were only just learning to use the new techniques themselves at that time.

\section{Implementation of the Course}

Gradually, the course has transformed from traditional weekly lectures and exercises towards providing teaching and assignment material online backed up by an extensive utilization of peer-reviews. In the most recent course with 1300 students in autumn 2019, the three core teaching instruments were:

1. Core substance material

- a new package weekly

- available electronically online

- non-compulsory lectures summarizing the material and giving opportunity to ask questions and discuss

2. Assignments (the course is passed based on these), completion of which are assisted by

- an online discussion forum, and

- non-compulsory hands-on labs.

3. Peer-reviewing

- detailed instructions of how the students are to mark the task

- a student has the possibility to challenge the received review and exchange messages with the reviewer

- meta reviewing performed by teaching assistants

Even though the transition is towards flipped learning and course material (including course pages, slides, and videos) is provided online, also traditional style lectures are still given. There is a small percentage of students who want to hear the teacher to summarize the material and lectures also give students the opportunity to discuss the material. However, the proportion of these students is decreasing all the time. Fifteen years ago there were about $20 \%$ of students attending the lectures, this year the figure was less than 5\%. In these big courses, this makes still tens of students.

Each lecture introduces a new assignment. Students are encouraged to accomplish the assignments independently. One source for help is an online discussion forum, where students ask and give help to each other. The forum is moderated by a teaching assistant. WETO could be used as platform for the forum, but Moodle is used just to teach to students to use another LMS, which is widely used in the university. Assignments are accompanied by a list of hints and pointers to helpful resources for completing the assignments. In addition to these sources, face-to-face assistance is also provided: teaching assistants are available at certain times to advise and help in computer labs.

After the students' assignments are returned, a model solution and detailed instructions for peerreviewing are published. Students are asked to do self-review of their own assignment and peer-reviews of two anonymous fellow students, The instructions reinforce the learning points and sometimes they 
also complement the taught topics with new knowledge. The completion of peer-reviews is followed by a meta-review phase, where the teachers perform a review of reviews. WETO, provides a visual means to easily spot potentially problematic cases. Students have a possibility to challenge the review if they disagree with it and discuss anonymously with the reviewer. If the students do not reach agreement, the teacher acts as the referee and makes a decision about the marking.

Originally, peer-reviewing was introduced to manage assessment on a big course, but with the comprehensive support of Weto the role of peer-reviewing has evolved to be an important teaching instrument in its own right.

\subsection{Peer-Review Support Provided by WETO}

Without peer-reviews the amount of time required for assessment in the CSO course would be excessive. Each assignment comprises of several tasks, and a submission often consists of several documents per assignment. In sum, in a typical course there are thousands of tasks to be assessed. For example, in a course of 500 students and 10 assignments, there are roughly 25000 tasks to be reviewed $(500 \cdot 10 \cdot 5=$ 25 000). The assignments are typically such, that automatic reviewing of them would be very complicated if not impossible. In consequence, peer-reviews are the only feasible method to perform and fulfill simultaneously the requirement of continuous assessment.

Each student evaluates a pre-defined number of peer assignments, and the identities of the students submitting the assignments and conducting the peer-reviews are known only by the teachers of the course.

For courses like CS0, the LMS is a necessary support for peer-reviews. The support WETO provides for a teacher has evolved over the years to include, e.g. the following functionality. It

- provides an easy interface to create the reviewing and marking instructions,

- $\quad$ automates the distribution of assignments (for students to be reviewed),

- anonymizes the assignments,

- $\quad$ keeps the process on schedule (but at the same time allows individual changes to the schedule),

- $\quad$ provides visual support to manage meta-reviews of hundreds of students (Figure 3),

- manages marking statistics (such as calculating the mark from the grades given by peers), and

- $\quad$ takes care of book-keeping and marking the whole course.

When scanning through the given peer-reviews, the teacher notices at a glance when the given points for an assignment differ. For example, the student number 146 has received exactly the same points from her peers, which she has given herself. Student number 140 has been stricter on himself than the peers have, and student number 145 has given himself more than the peers have. Color coding helps to spot easily the un-completed reviews (yellow) and the reviews that meta reviewers rejected are displayed in red.

From the student's point of view, WETO tries to minimize the additional workload of peer-reviewing by

- $\quad$ simplifying access to the assignments to be reviewed

- $\quad$ giving the reviewing and marking instructions to students when and where they are needed,

- $\quad$ supporting the giving of points for different tasks,

- $\quad$ calculating automatically the overall mark of an assignment,

- $\quad$ supporting challenging a received grade and discussing it anonymously with the reviewer, and

- $\quad$ giving a possibility to follow and retrace their progress on the course. 
Figure 3. Teacher's view of some (approx 70 of 1300) of the peer-reviews of on assignment.

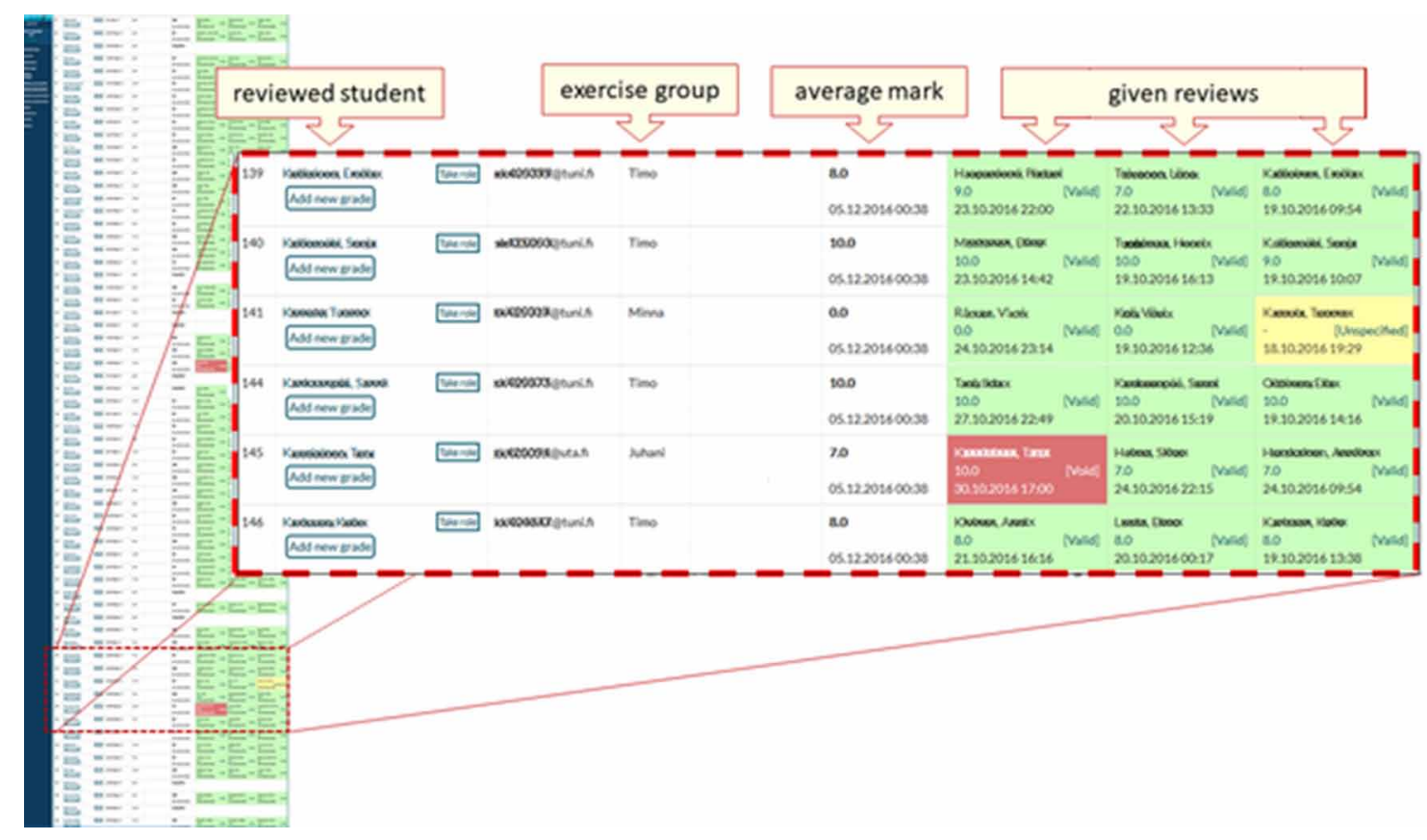

In the student's view (close-up (c) in the Figure 4) we can see a situation where a student is asked to give a review for a task based on the presented reviewing instructions. The student should give both written comments, and number of points for the reviewed task.

The development of WETO originally started in 2004 at Tampere University. In 2012, the development of the next generation of WETO led to almost a complete reimplementation of the original system. From a technical point of view, WETO is a Java EE Servlet web application that stores its data in a PostgreSQL relational database. WETO is fairly resource-efficient based on its capability of hosting the whole CSO course with more than 1200 participants in a single basic virtual server with one CPU and no more than 4 GB RAM. During the academic year of 2018 -2019, WETO was used in 28 courses by roughly 2500 unique users. In fall 2019, the user interface components are modernized using Vue.js and the source code of WETO is scheduled to be released.

\section{RESULTS AND DISCUSSION}

Formative assessment is a crucial part of flipped learning. In mass courses, such as CS0, self- and peer-reviews provide a realistic and affordable means for continuous formative assessment. While the number of students attending the CS0 course increased from about 400 to over a thousand, the teaching resources have remained roughly the same. Yet, we managed to stick to the course principle to teach hands-on-skills by 'learning by doing'. The following table illustrates the main points in the evolution of the course during 2004-2018.

In 2011, there was an unsuccessful experiment to run the course using Moodle, which is discussed in more detail in section 4.5. Student feedback had emphasized that peer-reviewing increases workload. As 
Flipped Learning With Peer Reviews in an Introductory CS Course

Figure 4. Student's view, when giving a peer-review, (a) when opening an assignment A4 for peerreviewing, (b) after clicking the first given assignment to peer-review, and (c) a close-up of instructions for reviewing one task in the assignment

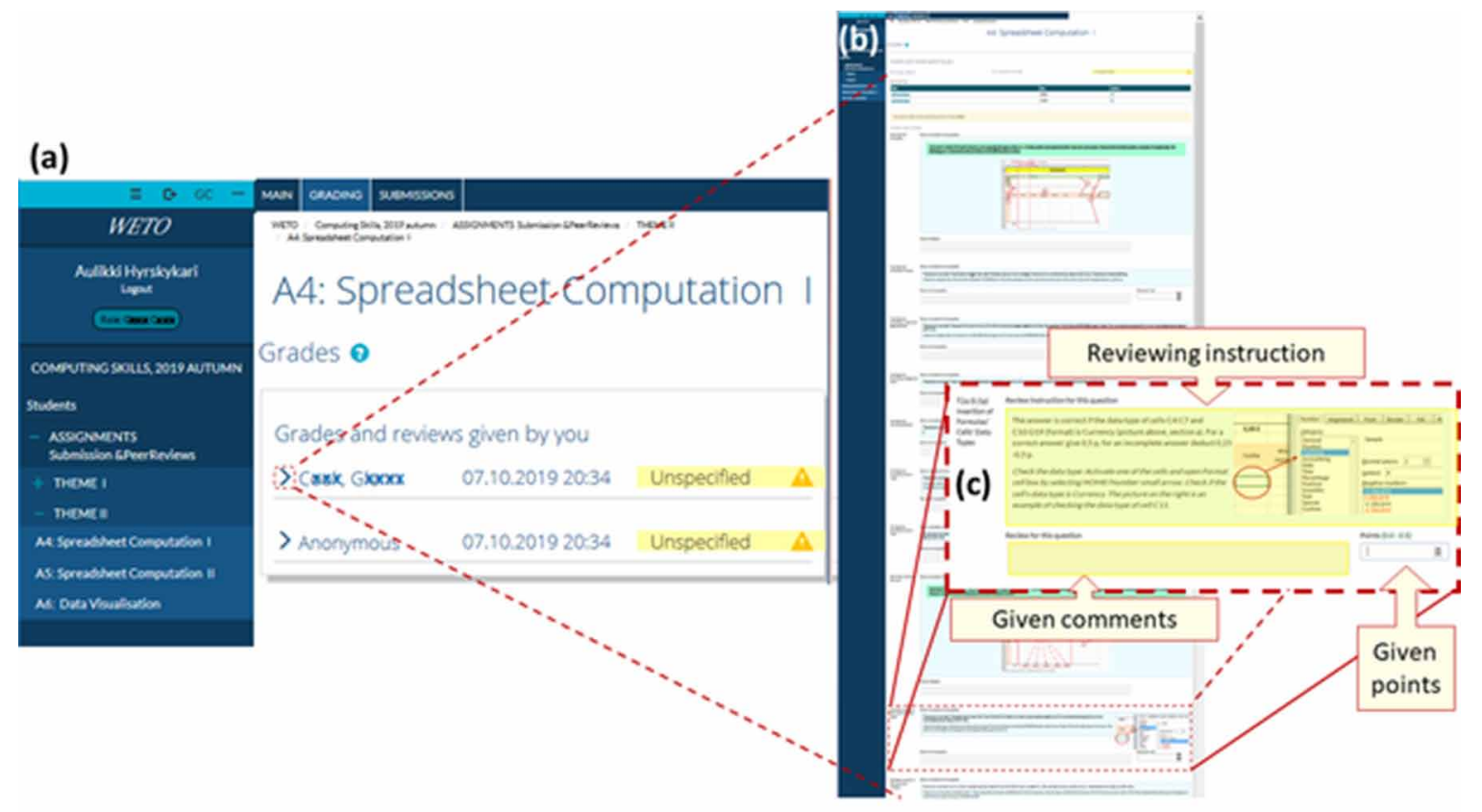

Table 1. Main changes between implementations of the CSO course

\begin{tabular}{|c|c|c|c|c|c|c|}
\hline & 2004 & 2005 & 2011 & 2016 & 2018 & 2019 \\
\hline LMS & $\begin{array}{l}\text { Teacher } \\
\text { centered, } \\
\text { course } \\
\text { pages }\end{array}$ & $\begin{array}{l}\text { Teacher } \\
\text { centered, } \\
\text { course pages, } \\
\text { WETO }\end{array}$ & $\begin{array}{l}\text { Teacher } \\
\text { centered, } \\
\text { course pages, } \\
\text { Moodle }\end{array}$ & $\begin{array}{l}\text { Student } \\
\text { centered, } \\
\text { course pages, } \\
\text { WETO (Moodle) }\end{array}$ & $\begin{array}{l}\text { Student } \\
\text { centered, } \\
\text { course pages, } \\
\text { WETO (Moodle) }^{*}\end{array}$ & $\begin{array}{l}\text { Student } \\
\text { centered, } \\
\text { course pages, } \\
\text { WETO (Moodle) }^{*}\end{array}$ \\
\hline Schedule & Fixed & Fixed & Fixed & Fixed & $\begin{array}{l}\text { Flexible within } \\
\text { limits }\end{array}$ & $\begin{array}{l}\text { Flexible within } \\
\text { limits }\end{array}$ \\
\hline $\begin{array}{l}\text { Task selection } \\
\text { within } \\
\text { assignments }\end{array}$ & $\begin{array}{l}\text { Assigned } \\
\text { by teacher }\end{array}$ & $\begin{array}{l}\text { Assigned by } \\
\text { teacher }\end{array}$ & $\begin{array}{l}\text { Assigned by } \\
\text { teacher }\end{array}$ & $\begin{array}{l}\text { Assigned by } \\
\text { teacher }\end{array}$ & $\begin{array}{l}\text { Self-chosen by } \\
\text { student }\end{array}$ & $\begin{array}{l}\text { Self-chosen by } \\
\text { student }\end{array}$ \\
\hline $\begin{array}{l}\text { Assessing } \\
\text { assignments }\end{array}$ & $\begin{array}{l}\text { Teacher } \\
\text { reviewed }\end{array}$ & $\begin{array}{l}\text { Peer- } \\
\text { reviewed, } \\
\text { offline } \\
\text { review } \\
\text { instructions }\end{array}$ & $\begin{array}{l}\text { Peer- } \\
\text { reviewed, } \\
\text { offline review } \\
\text { instructions }\end{array}$ & $\begin{array}{l}\text { Peer-reviewed, } \\
\text { integrated } \\
\text { review } \\
\text { instructions }\end{array}$ & $\begin{array}{l}\text { Peer-reviewed, } \\
\text { integrated review } \\
\text { instructions }\end{array}$ & $\begin{array}{l}\text { Peer-reviewed, } \\
\text { integrated review } \\
\text { instructions, } \\
\text { challenging and } \\
\text { negotiations }\end{array}$ \\
\hline $\begin{array}{l}\text { Peer } \\
\text { collaboration }\end{array}$ & $\begin{array}{l}\text { (not } \\
\text { supported) }\end{array}$ & $\begin{array}{l}\text { Offline } \\
\text { support }\end{array}$ & $\begin{array}{l}\text { Offline and } \\
\text { online } \\
\text { support }\end{array}$ & $\begin{array}{l}\text { Offline and } \\
\text { online support }\end{array}$ & $\begin{array}{l}\text { Offline and } \\
\text { online support }\end{array}$ & $\begin{array}{l}\text { Offline and online } \\
\text { support }\end{array}$ \\
\hline
\end{tabular}

*Moodle is used only for the discussion forum 
a response, the review instructions were integrated into WETO in 2016, as shown in Figure 4. In 2018, the assignments were divided into three themes. The assignments contain easier and more demanding tasks, and the students are given an opportunity to select the tasks from which they think benefit the most.

Another criticism from student feedback was the disappointment for the erroneous or "lazy reviews" they got from some peers. Students wanted to have a possibility to challenge the given review, if needed. This would also raise the quality of the reviews, and the function was implemented in WETO in 2018. A raised challenge initiates a negotiation phase between a reviewer and a reviewee. On the CS0 course it is used now (year 2019) for the first time, but it was tested on a smaller course already last year. Results of the first use are reported in 4.3.

The CSO course has gradually migrated more and more towards flipped learning and assessment has become entirely formative. Figure 5 reflects the course development on the dimensional view of didactic approaches (Figure 1.).

\subsection{Students' Feedback of the CSO Course and Applied Peer-Review Practices}

Students feedback about the course is collected during the last exercise. The feedback from the 2018 CS0 course shows that the course is considered laborious $(\mu=4.2$, var $=0.71)$, that students put a significant amount of effort to complete the course $(\mu=3.8$, var $=0.68)$, and that, in consequence, they have learned a lot $(\mu=3.7$, var $=0.82)$. However, the results polarize the most, when the students consider the effectiveness of teaching methods $(\mu=3.1$, var $=1.0)$, peer-reviewing being a crucial part of them. The qualitative course feedback when asked to describe the course with ten words for the future students reveal the students' opinions in more detail.

Figure 5. The evolution of the CSO course situated in the continuum of flipped learning

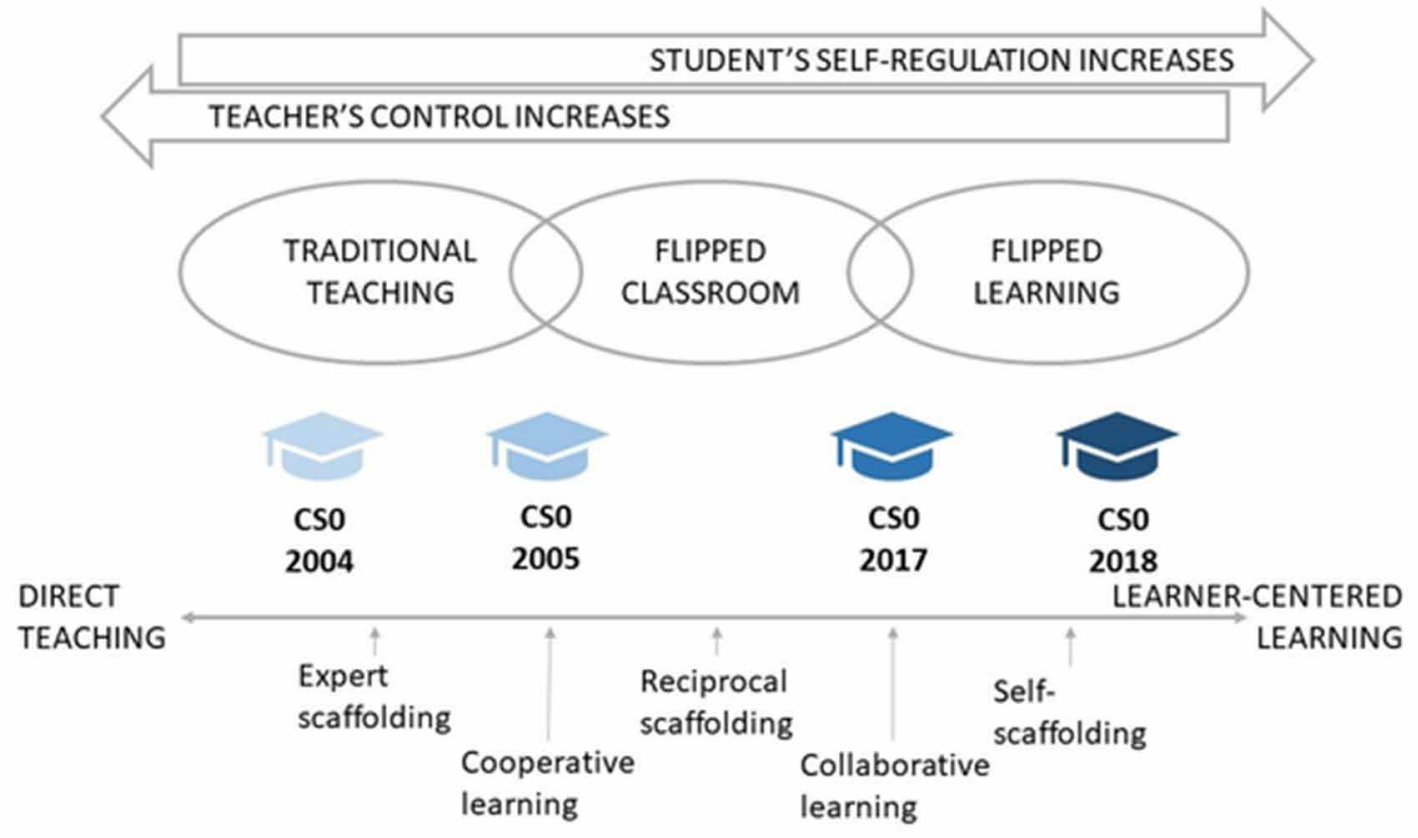


Flipped Learning With Peer Reviews in an Introductory CS Course

First samples of the positive ones:

A useful course. Even if you already have good IT skills, you will learn something new.

Helpful in every way. Even though a student might think he can, there are many new things to comprehend.

Precise work that is yet worth your time. After the course you will be wiser.

An intensive, efficient, labor-intensive, but it advances greatly your CS skills.

Be positive, be prepared to spend a lot of time, but you will learn a lot!

A very hard but useful course.

The other side of the coin is the frustration arising from the workload, in particular, if a student has multiple parallel commitments:

Really laborious course, it distracts you from your own study program courses.

A lot of work in vain.

Extremely useless, completely useless tasks, peer-reviews are bullying.

Huge amount of effort compared to credits. Many exercises focused on useless topics.

When the opinions were grouped as being only positive (like the first group of comments above), only negative (the second group), and the ones containing both, positive and negative, the proportion of positive opinions was $51 \%$, the negative $9 \%$, and the mixed opinions $41 \%$.

Actually, the proportions have typically been better in previous years. For example in 2016 the corresponding percentages were $78 \%, 4 \%$, and $18 \%$. A plausible explanation to this clear reduction of positive opinions is that a big share of the course material and assignments were in 2018. First time, not that polished versions, and the unusually big workload resulted to delays when publishing material stirred up the students' criticism.

The quantitative feedback from 926 students in 2018 is shown in Figure 6, where the assessed topic is presented under the bars in the scale from 1 to 5 .

The qualitative feedback confirms the quantitative result of the laboriousness; however, the majority of participants thinks they have learned a lot, but a few are displeased with the topic selection, and consider it partly useless, maybe because they are adequately educated in those already. In addition, the peer-review practice divides the opinion.

Next, the focus is moved to peer-reviews in particular, previous comments touched the topic slightly (seen as 'bullying'). Annoyed comments also include the variants of considering this as laziness of the staff: 
Figure 6. The quantitative feedback of CSO course (N=926), year 2018

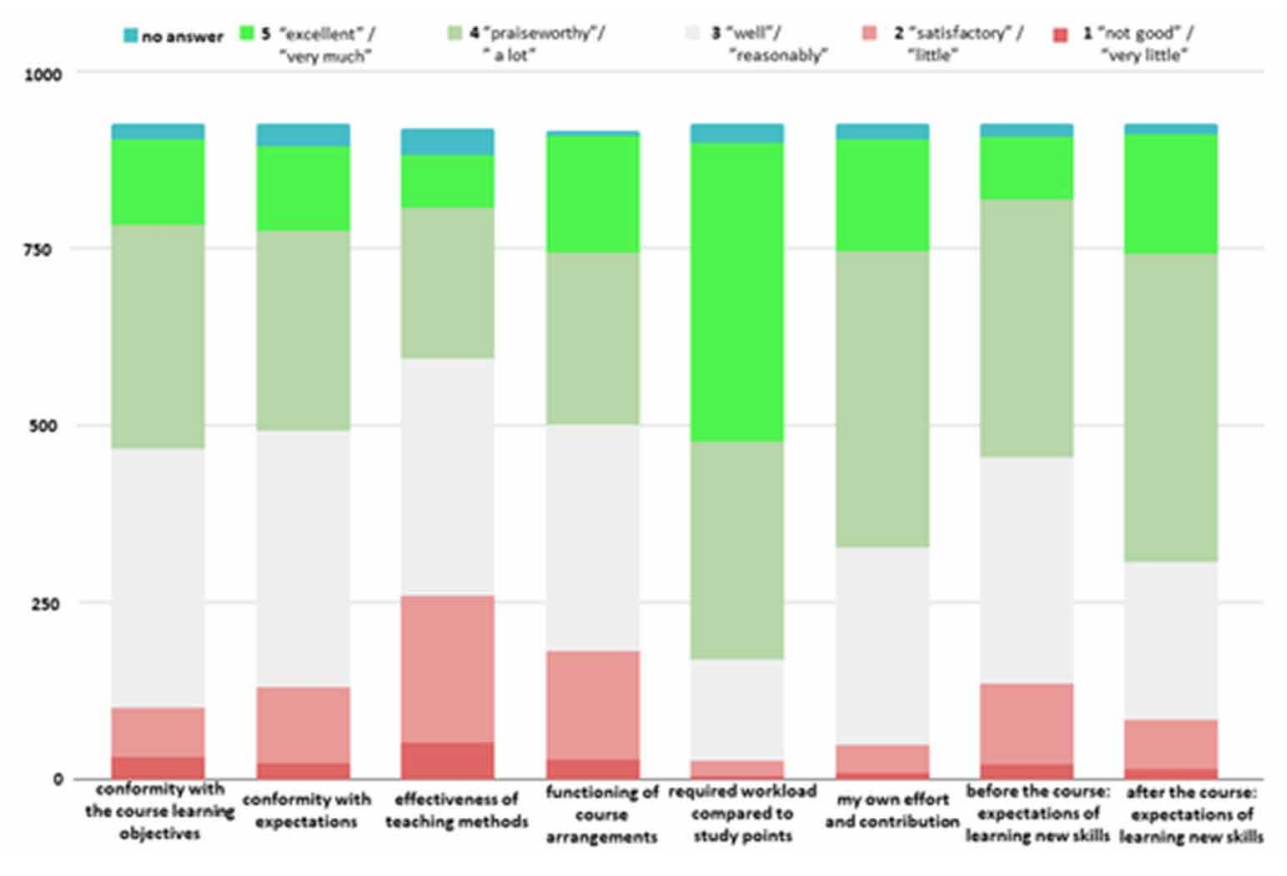

Could tasks and grades be automated if the teachers don't bother to check themselves?

After the initial resistance, many students have accepted the system, as can be read from the following feedback:

I think peer reviews work very well against my own prejudices. WETO was a convenient and equitable place for all work and submissions. My own course may have been hampered by the work I did on Mac and LibreOffice (instead of using the CSO classroom offering), but on the other hand, these are the ones I will continue to use so I'd better learn.

Prompt feedback, self-and peer-review, iterating three times the right answers just force you to learn.

A few students understood the benefits from the viewpoint of course arrangements:

One of the best-organized and most robust mass courses where I've been. One can notice that the implementation has been considered and refined. Help would have always been available and had been easy to find. Good job from everyone.

In overall, the peer-reviewing system is perceived very differently: one end gets annoyed because of 'work in vain', unfair or unreliable grading, and an uncertainty as a peer-reviewer, if the assessment instructions or own substance knowledge are considered inadequate. The opposite end understands the course context, the extensive amount of assessment needed, thus, the induced necessity of students' involvement - a few highlight self- and peer-reviews as an efficient learning tool per se. 
Flipped Learning With Peer Reviews in an Introductory CS Course

Wilson, Diao, and Huang (2015) identify the same perceptions as this work. In cons, the students regard the peer review tool as 'unfair, time-consuming and unprofessional', the pros itemize the development of students' meta-cognitive attributes, and collaborative pedagogical potential of the whole group. In conclusion, Wilson and colleagues regret that due to 'the competitive atmosphere that circulates, and is quietly encouraged', the peer-review system (i.e., Moodle's Workshop tool) is not living up to its potential. In this research, the competitive atmosphere is not recognizable, excluding such peer-reviews, where negotiations provoke a duel of the best argument winning (see Ch. 4.4).

\subsection{Best Practices for Peer-Reviews}

Successful peer-reviewing system requires clear guidelines for making evaluations. Strict deadlines are needed, yet with a warranty of individual rescheduling deadlines in case of problems. The optimal number of reviews for students has turned out to be a self-review followed by two peer-reviews. Evaluating one's own work first makes the subsequent evaluation of other's work easier. Additionally, students are motivated in looking at how much they score, so hopefully they are also well motivated to follow the review instructions. The reason to give students their own completed assignment to review, is that it appeared that after this the quality of the two peer-reviews is better. Self-reflection is valuable in itself, but also the students are more motivated to go through the model answer and reviewing instructions in detail when marking their own assignment as well.

Setting up a course discussion forum was also invaluable and keeps emailing between course staff and students under control. The exploitation of discussion boards does not start automatically; students must be guided to use it right from the start, and to visit the forum regularly. One task is that they must write one comment in the area. The course staff must pay attention and work hard to create a positive, accepting, and stimulating atmosphere. Many students have commended it, for example:

Discussion area was excellent! I wouldn't have been able to get through without it. Special thanks for the teacher, thanks in particular for encouraging answers.

The reliability of the reviews must be supervised. Meta-reviews evaluate students' peer-reviews, and the reviews are regularly done by the course staff. They are needed to demonstrate students the principles of a good review, and the importance of their input. However, the workload of meta-reviews is only a fraction of what would be required from teacher assistants to produce the same quality reviews. In anticipation of future with academic writing, the peer-reviewing gives readiness to give and accept feedback. Therefore, the peer-reviews prepare for academic values and give insight into the peer-review process as a whole.

In CS0, peer-reviews have been applied since 2005, and they have been proven to be an efficient and functional assessment tool for very large student groups. Fortunately, the system works well from the viewpoint of both pedagogy and fewer teaching resources. Similar formative assessment practices pioneered by the CSO are currently emerging in pedagogy, thereby making a virtue out of necessity. For instance, the Finnish education system addresses the importance of self-regulation, meta-cognitive skills in preparation for learning to learn, and new assessment practices that support the process. In primary education, the Ministry of Education requires students to observe both the study progress of their own and the whole group, which creates the conditions for students' self-reflection and peer-review skills 
Flipped Learning With Peer Reviews in an Introductory CS Course

development (Finnish National Board of Education, 2014). In the secondary education, the requirements for the assessment contain the following aspects:

The student's work, learning and competence development should be evaluated in a comprehensive way. [...] The purpose of student assessment is to guide and encourage learning and to develop the student's prerequisites for self-assessment. The student has the right to be informed about the criteria used in the assessment and how the criteria are applied. In addition, students must be given an opportunity to train self-evaluation. (Finnish National Board of Education, 2015)

The assessment practices of CS0 are in line with the requirements of Finnish education, and the theoretical framework of this study. The course content is tailored for equipping students with the basic knowledge of ICT. In addition, such secondary learning objectives as collaborative learning and peerreview practices prepare students for future working and thinking skills: problem solving, decisionmaking, learning to learn and meta-cognitive skills catalyzed by self-reflection.

\subsection{Negotiations}

The negotiation is conducted on a simple anonymized discussion forum provided by WETO separately for each challenge. If this negotiation remains unresolved, the case escalates automatically to the course personnel. It was anticipated that students would not make extensive use of this possibility, and indeed, this escalation happened in about only half of the cases.

In 2018, challenges were first used in Introduction to Big Data Processing course (Hyyrö, 2018). An excerpt of course interactions illustrates the frequency of challenges and the nature of negotiations. Data covers three training sessions with a total of 18 exercises, and about 50 participants. Altogether there were 665 peer reviews, 68 of which were challenged, i.e., roughly $10 \%$. Of these, 39 came to an agreement, requiring the teacher to resolve the remaining 29 cases. Out of these 29 cases, 9 concerned completely missing peer reviews (the assigned reviewer left the course, etc.) and would thus have ended up to the teacher in any case.

When the content of the negotiations is analyzed, the histogram of the discussion lengths illustrates roughly the character of these negotiations, see Figure 7.

A 0-length negotiation (10 cases) is an interesting phenomenon, it may happen as a reminder from a reviewee when a reviewer has not done the review, but a reviewee does not bother to write any message. 1-length negotiations can be categorized as reminders as well but with a content this time, such as 'Grade missing', or 'No review so far'. 2-length discussions are either refreshed reminders, or reviewers' acknowledgements, apologies, and prompt executions of the demanded peer-reviews. Replies are also quite concise, such as: 'Sorry for the delay, I forgot the deadline. Your answer should have been reviewed now.' Had a person quit the course, his peer-reviewees would convey back to the course personnel.

More interesting negotiations have the length of three or more messages. Some of them have certain resemblance with the discussions with the HelpDesk, the technical help of Tampere University. Students try to solve the problem together, cooperatively. In the end, when the consensus is reached, the last statements may be as gratified as this::

Yes, I also think this comes down to the interpretation of the guidelines. If we forget about the command line parameter problem, for sure your program solves more than $80 \%$ of the question. However, I 
Flipped Learning With Peer Reviews in an Introductory CS Course

Figure 7. The challenge histogram $(N=68)$ based on the discussion lengths

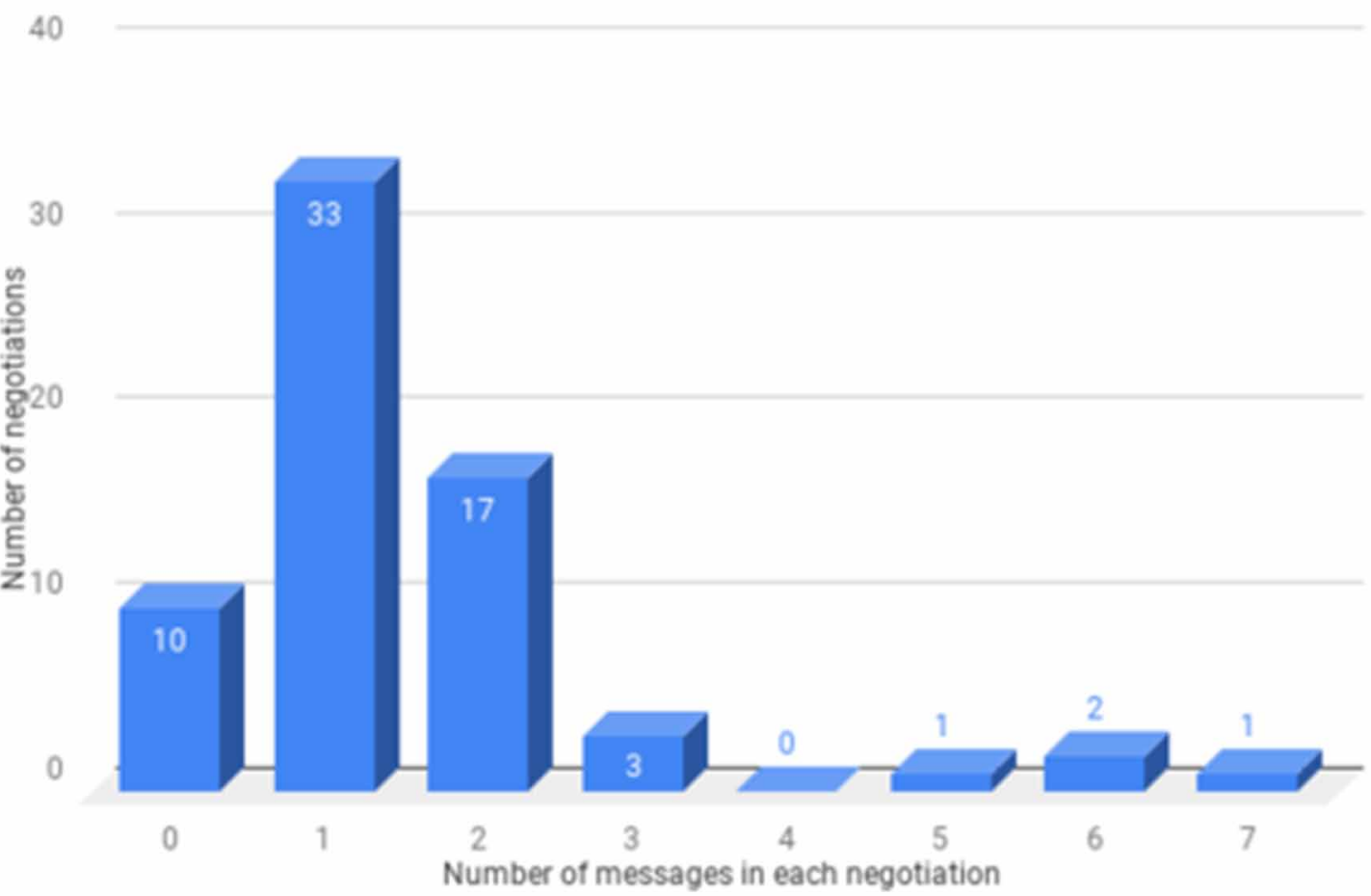

consider it to be such a crucial part of the assignment, that I think the score can't be 3. I also still think that because the arguments for giving 1 point mention the crashing of program (which your does, when run as instructed), that 1 point would also be acceptable score. And no problem. I am also not trying to annoy you. I really just think this is how the peer review instructions should be interpreted. I also must say that you have made good arguments and this has actually been a pleasant debate.

\subsection{Comparison of Self- and Peer-Review Services in the Selected LMSs}

In the comparison of peer-review support of other LMSs used in Tampere university, WETO is taken as a baseline. The best attractions of WETO comprise, e.g., flexibility in tailoring the system to meet the typical workflow of a course and in arranging deadlines and other student issues, automatic assessment, and especially versatile self- and peer-review options. The next sections will shortly introduce the corresponding peer-review functionality of other LMSs, Moodle and A+, used by Tampere University, and highlight the differences where appropriate.

\section{Moodle and its Workshop Module}

Moodle is a free and open-source system with an abundant provision of middleware, and it is widely used. In general, efforts have been made to eliminate the coexistence of several platforms, thus, in 2011, the use of Moodle was forced externally by the university administration. In Moodle, the Workshop module 
provides the peer-review functionality. Unfortunately, the functionality of Moodle was not considered adequate from the viewpoint of the $\mathrm{CS} 0$ requirements.

For example, the review process with pre-defined and fixed due dates was too inflexible, and exceptions were hard to handle. Overall, the usability of Moodle peer-review was considered poor, and it contained a lot of complexity that is inherent characteristic of configuration and settings of Moodle. An excerpt from the report written by the staff after trying to use Moodle for peer assessment exemplifies this:

The system is logically confusing. There is an insanely large number of different settings: e.g. In the Workshop module, the rights of the course staff alone are managed through a page with almost three hundred features. It is often impossible to find the setting that results in some strange view (e.g., editing the evaluation report seen by the students, and if lucky enough to find the right combination of settings, but when - after a big job I thought I was pretty successful - it looks different for students.)

In addition, the comments from the course personnel highlight Moodle's slowness:

Moodle is sometimes very slow, at least to the teacher - ..., and it takes considerably more time than what you are used to with WETO (can this be improved in any way, it is probably due to the Moodle implementation architecture?)

.. and other gaps in usability:

In a large course with hundreds of students, the outlook is really awkward, often nearly impossible to use. (e.g., it is impossible to look at individual student scores in the summary of student results).

\section{A+ and Rubyric of PRP}

A+ itself does not contain any peer-review options, but it provides Learning Tools Interoperability (LTI) protocol for the integration of various tools. LTI protocol ensures interoperability between LMSs in order to launch external online learning activities and submit grades back to the LMS. LTI is defined by IMS consortium (IMS Global Learning Consortium, 2019). For example, A+ can be enhanced with the Rubyric service that is utilized in the programming courses of Aalto University. Rubyric is a web-based evaluation tool that provides sections for giving feedback. The tool was initially developed in Tampere University by Ahoniemi and Reinikainen (2006), and the name of the tool is ALOHA. The tool made a cyclic tour in Aalto University, where it was re-implemented in Ruby, and renamed as Rubyric. The functionality remained about the same: feedback may be semi-automated by providing a term/appraisal bank. Furthermore, the rubric framework may be enhanced with a term bank comprising both assessment criteria and ready-made success/failure sentences (Vironmäki, 2016).

In addition to Rubyric, Pietari Heino (a graduate of Tampere University) implemented a peer-review module for A+ referred simply as PRP (Heino, 2019). The system is implemented in Python, and it utilizes Django web framework, similarly to the whole A+ system. It is a micro-service that uses LTI in integration to $\mathrm{A}+$, but it can be also used as a standalone application. In the peer-review system, a teacher first creates a course, where students can submit their work for their peers to be reviewed. A group mode is also supported. In addition to inter-group peer-reviews, the first intra-group reviews were 
carried out in 2018 with the goal of detecting the students who do not contribute to the process (Järvinen, Niemelä, and Virta, 2019).

The use of the A+ peer-review system has been experimental after its introduction in 2018. The initialization of a course was not yet fully automatized, but required the developers' assistance. Thus, the current state can be described as work-in-progress. Users have been quite content with the functionality, though. In the future, the A+ system will also support peer-reviews of source code directly in git repositories by granting reporter rights temporarily for a reviewing student; after the review period is over, these rights are removed. This peer-review option is very welcome in the domain of computer science.

\section{CONCLUSION}

\section{RQ1: What are the means to increase formative assessment in the introductory CS course with plenty of exercises that are difficult to assess automatically?}

The paper presents the self- and peer-review practices of the CSO course that has been iteratively developed since year 2004, and is still actively being developed further. Best practices include constructively aligned instructions and a computer-assisted review process with well-planned rubrics, the recommendation of three reviews (self-review plus two peer-reviews), efficient meta-reviews and interventions in case of any flaws right in the beginning of the course, and negotiations as a means for students to intervene in the case of unfair reviews.

In spite of the reduced resources such as personnel and micro-class reservations, the same level of the learning outcomes has been achieved. In this respect, the course with flipped online exercises with peer-reviews works well. In addition, peer-reviews seem to increase the community feel, in conformance of the earlier results (Niemelä, 2012).

\section{RQ2: How are the CSO teaching arrangements, and the self- and peer- review practice in particular perceived among the course participants?}

The course is considered as laborious but rewarding. Peer-reviews divide opinions, a few students are displeased, mainly because of the extra work and low confidence in peers as reliable reviewers. In contrast, some students are surprised by the feasibility of the practice and recognize its pedagogical potential.

\section{RQ3: What is the current level of support for self- and peer-reviews in the selected LMSs?}

For the specific needs of the CSO course, WETO provides the best user experience. Negotiation is a new feature, and experiences are currently being collected, analyzed and elaborated as new development ideas for WETO in the spirit of DBR. 
Flipped Learning With Peer Reviews in an Introductory CS Course

\subsection{FUTURE RESEARCH}

The negotiations provide plenty of material that is worthy of more focused research. Further development of peer-review practices e.g., credibility of reviews, and the exploitation of learning analytics (LA), are potential research topics. In addition, measuring learning outcomes, balancing contribution between group members, and smoothing out teamwork are in target, where the benefit of intra-group peer-review, and other indicators would be worth checking out.

Based on the students' feedback the biggest problems of peer-reviews are perceived unfairness, the extended workload, and low motivation, whereas the teachers are more concerned about the learning outcomes, and the full exploitation of peer reviews' pedagogical potential, as described by Wilson et al. (2015). To make reviews fairer, the peer-review rubrics are of paramount importance, provided by WETO, as well as A+ Rubyrics. In addition, also the peer-reviews should be evaluated. Meta-reviews are made by the course personnel, in particular, in the beginning of the course. The meta-reviews might be expanded, so that students may evaluate, e.g., the educational value, fairness, and structure of peerreviews. Good reviews deserve rewarding.

In motivating students, and in decreasing the assessment effort, learning analytics are exploitable. By collecting data of user's behavior, the data can be refined as better user experience of the system. The very purpose of learning analytics (LA) is to collect information about the student's learning and learning environment. The analysis is conducted by examining digital traces that user leaves to the system. The analysis necessitates a sufficient amount of data to be collected in a timely fashion. The definition of LA by Siemens and Gasevic (2012) lists the phases of measuring, gathering data, analyzing and reporting the results, and on the basis of this, understanding the students and optimizing the learning environment. Indispensably, an appropriate interpretation must follow and is a crucial part of the analysis, as the authors emphasize, and only the interpretation enables to understand the students' activities on the platform and influence the outcome.

In addition to LA, references talk about 'teaching analytics' (TA). For example, Prieto, Sharma, Dillenbourg, and Jesús (2016) coin a following description: 'TA refers to methods and digital tools to help teachers analyze and improve educational designs a priori to delivery.' The barrier between LA and TA is partially artificial, thus, the concept of Teaching and Learning Analytics (TLA) has been introduced to merge the complementary sides of a coin (Sergis and Sampson, 2017). According to the authors, TLA is an emerging research field that aims at supporting teachers during the process of inquiry. TLA grants an insight on the flow of learning and assessment activities as well as the actual analysis and classification, monitoring the teachers' contribution in learning and discussion activities, investigating the impact of their educational design to a learner, both as a complete product, as well as in specific elements of it. However, only few TLA works have explicitly addressed the aspect of supporting teachers' reflection on the delivery of the educational design. In addition, only a little TLA research attention has been given on how to provide recommendations to teachers for translating the analyzed data to functional reflecting actions on their educational design and delivery (Mor, Ferguson, and Wasson, 2015).

Like the gradual progress towards more student-centered and self-regulated learning in pedagogy, LA should not only provide control and monitor tools for teachers, but instead, enable students to monitor their own learning process, and to empower them in taking ownership of their progress. The goal is an autonomous learner who is led by an intrinsic motivation, not externally by instructors or ECTS (Deci and Ryan, 2010). In exploiting the LA data, LMS and learning content could be personalized, customized and differentiated to match better the level of current skills of students. In SDT theory, interactions 
Flipped Learning With Peer Reviews in an Introductory CS Course

and social relatedness are considered motivational factors. Thus, the LMS could also provide gamified content and opportunities for collaboration, not only during peer-reviews.

\section{ACKNOWLEDGMENT}

Thanks to the Academy of Finland (grant No303694, i.e., Skills, education and the future of work) for their financial support.

\section{REFERENCES}

Ahoniemi, T., \& Reinikainen, T. (2006). ALOHA - a grading tool for semi-automatic assessment of mass programming courses. In Proceedings of the 6th Baltic Sea Conference on Computing Education Research: Koli Calling 2006, pp. 139-140. ACM.

Anderson, T., \& Shattuck, J. (2005). Design-based research: A decade of progress in education research? Educational Researcher, 41(1), 16-25.

Bandura, A. (2010). Self-efficacy, Corsini Encyclopedia of Psychology. John Wiley \& Sons. doi, 10:9780470479216.

Baturay, M. H. (2015). An overview of the world of MOOCs. Procedia: Social and Behavioral Sciences, 174, 427-433. doi:10.1016/j.sbspro.2015.01.685

Beetham, H., \& Sharpe, R. (2013). Rethinking pedagogy for a digital age: Designing for $21^{\text {st }}$ century learning. Routledge.

Biggs, J. (1996). Enhancing teaching through constructive alignment. Higher Education, 32(3), 347-364.

Chen, Y., Wang, Y., \& Chen, N.-S. (2014). Is FLIP enough? Or should we use the FLIPPED model instead? Computers \& Education, 79, 16-27. doi:10.1016/j.compedu.2014.07.004

Collins, A. (1992). Toward a design science of education. In New directions in educational technology (pp. 15-22). Springer. doi:10.1007/978-3-642-77750-9_2

Deci, E. (1971). Effects of externally mediated rewards on intrinsic motivation. Journal of Personality and Social Psychology, 18(1), 105-115. doi:10.1037/h0030644

Deci, E., \& Ryan, R. (2010). Intrinsic motivation (pp. 1-2). The Corsini Encyclopedia of Psychology.

Finnish National Board of Education. Finnish National Curriculum 2014. (2014). Retrieved from https:// www.oph.fi/download/163777_perusopetuksen_opetussuunnitelman_perusteet_2014.pdf

Finnish National Board of Education. (2015). National Core Curriculum for General Upper Secondary Education. Retrieved from http://www.oph.fi/download/172124_lukion_opetussuunnitelman_ perusteet_2015.pdf 
Gros, B., \& García-Peñalvo, F. J. (2016). Future trends in the design strategies and technological affordances of e-learning. Learning, Design, and Technology: An International Compendium of Theory, Research, Practice, and Policy, 1-23.

Haatainen, S., Lakanen, A.-J., Isomöttönen, V., \& Lappalainen, V. (2013). A practice for providing additional support in CS1. In Proceedings 2013 Learning and Teaching in Computing and Engineering (pp. 178-183). IEEE.

Hattie, J. (2008). Visible Learning: A Synthesis of Over 800 Meta-Analyses Relating to Achievement. Taylor \& Francis; doi:10.4324/9780203887332

Hattie, J. (2012). Visible Learning for Teachers: Maximizing Impact on Learning. Taylor \& Francis. Retrieved from https://books.google.fi/books?id=xY-6MyDgks8C.

Heino, P. (2019). Github: peer-review platform. Retrieved from https://github.com/piehei/prplatform

Hyrskykari, A., Linna, J., \& Sand, A. (2017). The older course page of CSO, "Tietotekniikkataidot", Retrieved from https://coursepages.uta.fi/tiey4/

Hyrskykari, A., Linna, J., \& Sand, A. (2019). Course page of CSO, “Tietotekniikkataidot”. Retrieved from https://www.tuni.fi/studentsguide/curriculum/course-units/uta-ykoodi-27109?year=2019

Hyyrö, H. (2018). Introduction to big data processing, course homepage. Retrieved from https://coursepages.uta.fi/tieta17/

IMS Global Learning Consortium. (2019). Retrieved from http://www.imsglobal.org/toolsinteroperability2.cfm

JärvilehtoL. Koulu-uudistuksen uutisankka. (2018). Retrieved from https://ajattelunammattilainen. fi/2018/11/18/koulu-uudistuksen-uutisankka/

Järvinen, H.-M., Niemelä, P., \& Virta, U. (2019). Combining flipped ideas and online learning.

John, W. (2013). Moravec. Knowmad society: The "new" work and education. On the Horizon, 21(2), 79-83. doi:10.1108/10748121311322978

Koskinen, P., Lämsä, J., Maunuksela, J., Hämäläinen, R., \& Viiri, J. (2018). Primetime learning: Collaborative and technology-enhanced studying with genuine teacher presence. International Journal of STEM Education, 5(1), 12. doi:10.118640594-018-0113-8 PMID:30631702

Laurillard, D. (2013). Teaching as a design science: Building pedagogical patterns for learning and technology. Routledge. doi:10.4324/9780203125083

Mor, Y., Ferguson, R., \& Wasson, B. (2015). Learning design, teacher inquiry into student learning and learning analytics: A call for action. British Journal of Educational Technology, 46(2), 221-229. doi:10.1111/bjet.12273

Niemelä, P. (2012). Kerro, kerro kuvastin: tietokoneavusteinen itse-ja vertaisarviointi (in Engl. Mirror, mirror on the wall... computer-assisted self-and peer-reviewing)". (Master's thesis), University of Tampere, Finland. 
Flipped Learning With Peer Reviews in an Introductory CS Course

Norrena, J. (2016). Laaja-alainen osaaminen käytäntöön. Arviointi, opetuksen suunnittelu ja oppilaiden ohjaaminen. Keuruu: Otavan Kirjapaino Numminen, 1997.

OECD. (2015). Retrieved from https://www.oecd.org/finland/pisa-2015-finland.htm

Ørngreen, R. (2015). Reflections on design-based research. In Human Work Interaction Design. Work Analysis and Interaction Design Methods for Pervasive and Smart Workplaces, pp. 20-38. Springer. doi:10.1007/978-3-319-27048-7_2

Prieto, L. P., Sharma, K., Dillenbourg, P., \& Jesús, M. (2016). Teaching analytics: towards automatic extraction of orchestration graphs using wearable sensors. In Proceedings of the Sixth International Conference on Learning Analytics \& Knowledge. ACM.

Ryan, R., \& Deci, E. (2000). Self-determination theory and the facilitation of intrinsic motivation, social development, and well-being. The American Psychologist, 55(1), 68-78. doi:10.1037/0003-066X.55.1.68 PMID: 11392867

Saarinen, A. (2018). The relationships of temperament, character, and depressive symptoms with paranoid ideation. ( $\mathrm{PhD}$ thesis), University of Helsinki.

Schön, D., A. (1992). Designing as reflective conversation with the materials of a design situation. Knowledge-Based Systems, 5(1), 3-14. doi:10.1016/0950-7051(92)90020-G

Sclater, N., Peasgood, A., \& Mullan, J. (2016). Learning analytics in higher education. London, UK: Jisc.

Sergis, S., \& Sampson, D. G. (2017). Teaching and learning analytics to support teacher inquiry: A systematic literature review. In Learning analytics: Fundaments, applications, and trends, pp. 25-63. Springer.

Siemens, G., \& Gasevic, D. (2012). Guest editorial-learning and knowledge analytics. Journal of Educational Technology \& Society, 15(3), 1-2.

The Design-Based Research Collective. (2003). Design-based research: An emerging paradigm for educational inquiry. Educational Researcher, 5-8.

Toivola, M. (2018). Kunpa tämä olisi vitsi (in Engl. Wish this was a joke). Retrieved from http://mrstoivola.puheenvuoro.uusisuomi.fi/264388-kunpa-tama-olisi-vitsi

Toivola, M., Peura, P., \& Humaloja, M. (2017). Flipped learning. Käänteinen oppiminen. Helsinki, Finland: Edita.

Toivola, M., \& Silfverberg, H. (2015). Flipped learning-approach in mathematics teaching-a theoretical point of view. Matematiikan ja luonnontieteiden opetuksen tutkimusseuran tutkimuspäivät, pp. 93-102.

Toivola, M. (2016). Flipped learning-why teachers flip and what are their worries? Experiences of Teaching with Mathematics, Sciences, and Technology, 2(1).

Van den Akker, J., Gravemeijer, K., \& McKenney, S. (2006). Introducing educational design research. In Educational design research (pp. 15-19). Routledge. doi:10.4324/9780203088364 
Vanderhyde, J. (2019). Scaffolding assignments: How much is just enough? Journal of Computing Sciences in Colleges, 34(3), 55-63.

Vironmäki, V. (2016). Yhtenäinen web-oppimisympäristö ohjelmoinnin johdantokurssille. (Master's thesis), Tampere University of Technology, Finland.

Wang, F., \& Michael, J. (2012). Hannafin. Design-based research and technology-enhanced learning environments. Educational Technology Research and Development, 53(4), 5-23.

Whitehill, J., Williams, J., Lopez, G., Coleman, C., \& Reich, J. (2015). Beyond prediction: First steps toward automatic intervention in MOOC student stopout.

Wilson, M. J., Ming, M. D., \& Huang, L. (2015). I'm not here to learn how to mark someone else's stuff: An investigation of an online peer-to-peer review workshop tool. Assessment \& Evaluation in Higher Education, 40(1), 15-32. doi:10.1080/02602938.2014.881980 